\title{
COMUNICAÇÃO
}

\section{INFLUÊNCIA CLIMÁTICA SOBRE A PLASTICIDADE FENOTÍPICA FLORAL DE Catasetum fimbriatum LINDLEY}

\author{
Climatic influence on the Catasetum fimbriatum Lindley floral phenotipic plasticity
}

\author{
Cristiano Pedroso de Moraes ${ }^{1}$, Marcílio de Almeida $^{2}$
}

\begin{abstract}
RESUMO
Como tentativa de elucidar os fatores ambientais que controlam a plasticidade fenotípica floral de Catasetum fimbriatum Lindley, iniciaram-se estudos climáticos da espécie, com o acompanhamento de 45 indivíduos divididos em três tratamentos, com quinze indivíduos cada um. O primeiro tratamento foi instalado em casa-de-vegetação, onde predominou intensa luminosidade $\left(1300 \mathrm{a} 1900 \mu \mathrm{mol} / \mathrm{m}^{2} \mathrm{~s}\right)$, altas temperaturas $\left(38^{\circ} \mathrm{C}\right)$ e baixa umidade relativa do ar $(35 \%)$. O segundo tratamento foi instalado em ripado e submetido à baixa intensidade luminosa $\left(400\right.$ a $\left.650 \mu \mathrm{mol} / \mathrm{m}^{2} \mathrm{~s}\right)$, menor temperatura $\left(17^{\circ} \mathrm{C}\right)$ e a uma umidade relativa do ar mais elevada em relação ao primeiro (85\%). O terceiro tratamento foi mantido nas condições ambientais naturais (intensidade luminosa entre 500 a $800 \mu \mathrm{mol} / \mathrm{m}^{2} \mathrm{~s}$, temperaturas de $23^{\circ} \mathrm{C}$ e umidade relativa do ar de 65\%). Ao final do experimento, pôde-se constatar a grande adaptabilidade da espécie aos diferenciados ambientes, mediante formação de ecótipos.
\end{abstract}

Termos para indexação: Orquídeas, Catasetum, ecótipos, clima.

\begin{abstract}
As attempt of elucidating the environmental factors that they control the plasticity floral fenotipic of Catasetum fimbriatum Lindley, climatics studies of the species began, through of the accompaniment of 45 individuals divided in three installed treatments. The first fifteen individuals, they were conditioned at green house where intense brightness prevailed (1300 at $\left.1900 \mu \mathrm{mol} / \mathrm{m}^{2} \mathrm{~s}\right)$, high temperatures $\left(38^{\circ} \mathrm{C}\right)$ and it lowers relative humidity of the air $(35 \%)$. Such treatment was entitled treatment 1 . The other collected individuals that were put in the pot, and that they constituted the treatment 2 , they were submitted the low luminous intensity $\left(400\right.$ at $\left.650 \mu \mathrm{mol} / \mathrm{m}^{2} \mathrm{~s}\right)$, to a smaller temperature $\left(17^{\circ} \mathrm{C}\right)$ and a relative humidity of the highest air $(85 \%)$. The last fifteen individuals, presented the natural conditions of survival of the species, and they constituted in that way, the treatment 3 (luminous intensity between 500 at $800 \mu \mathrm{mol} / \mathrm{m}^{2} \mathrm{~s}$, temperature of $23^{\circ} \mathrm{C}$ and a relative humidity of the highest air of $65 \%$ ). At the end of the experiment, the great adaptability could be verified of the species to the differentiated environments, through the ecotipes formation.
\end{abstract}

Index terms: Orchid, Catasetum, Ecotipes and Climate

(Recebido para publicação em 17 de março de 2003 e aprovado em 21 de fevereiro de 2004)

O gênero Catasetum foi descrito em 1822 por L.C. Richard ex Kunth. Esse gênero já há várias décadas desperta interesses em botânicos e zoólogos, em razão de sua incrível adaptação à entomofilia (HOEHNE, 1938) e ao extraordinário trimorfismo em suas flores, presente na série Orthocatasetum. Essas plantas vegetam em segmentos de troncos de árvores velhas, onde existe acúmulo de material orgânico em decomposição, expostos geralmente à grande radiação solar (HOEHNE, 1938; MACHADO, 1998). Os autores citam ainda a existência de pseudobulbos grossos e bem desenvolvidos, relacionados com o armazenamento de água, que permitem a sobrevivência da planta nos períodos de estiagem.
Infelizmente a destruição contínua dos habitats naturais desse gênero põe em risco sua existência, justificando-se, dessa forma, estudos mais detalhados sobre Catasetum fimbriatum Lindley.

Além disso, em muitas áreas tropicais e subtropicais, a baixa quantidade de chuva reduz a disponibilidade da umidade apenas com o aumento do déficit de saturação da atmosfera, irradiação e a temperatura da folha, resultando no aumento da demanda de transpiração. O resultado da redução de umidade relativa do ar é um determinante primário do tipo de vegetação existente nessas áreas (MULKEY et al., 1996).

\footnotetext{
1. Mestre em Ciências pela Escola Superior de Agricultura "Luís de Queiroz" ESALQ/USP - Rua Dr. Amaral, 307 - Vila Bortoni - 13650-000 - Santa Cruz das Palmeiras, SP, Área de Concentração: Fisiologia e Bioquímica de Plantas.

2. Professor-Doutor do Departamento de Ciências Biológicas da Escola Superior de Agricultura "Luís de Queiroz" ESALQ/USP.
} 
A observação da ocorrência de estresse hídrico nos tipos de vegetação existentes nas áreas tropicais e subtropicais depende muito de cada espécie e de suas adaptações para suportar a época de estiagem. A perda de água por transpiração pode ser menor pela redução das áreas foliares e também pela diminuição da temperatura das folhas via redução da quantidade de radiação absorvida. A água, nesses casos, é mantida com a absorção pela raiz, em que fatores, tais como tensão exercida pela coluna de água devido à transpiração e à baixa resistência imposta pelo xilema, somada a outros mecanismos que evitam a perda de água, permitem um fluxo de água contínuo e necessário para a sobrevivência da planta.

Sem dúvida, a luz é um dos fatores ambientais mais importantes para o desencadeamento da maioria das reações fisiológicas de uma planta, como, por exemplo, o crescimento e o florescimento (COSGROVE, 1987).

São várias as pesquisas referentes às diferenciações estruturais e fisiológicas (plasticidades fenotípicas) entre plantas desenvolvidas em ambientes com luz abundante, seja ela natural ou artificial, e aquelas expostas a ambientes sombreados (RAVEN et al., 1996).

As plantas adaptam-se à intensidade da luz, regulando a morfologia de suas folhas e flores, sua composição e estrutura e seu estado fisiológico (principalmente no que tange à sua capacidade fotossintetizante), que como uma das conseqüências principais gera a alteração de suas vias metabólicas primárias e secundárias, originando, dessa forma, as mais diferentes respostas no que diz respeito aos seus processos anabólicos e catabólicos, na tentativa de permitir por meio dessas regulações o alcance de seu estado funcional máximo (GATES, 1981; NOBEL, 1991).

Com o presente trabalho, objetivou-se o estudo da plasticidade fenotípica floral de indivíduos maduros de Catasetum fimbriatum Lindley, sob a influência de variações quanto à umidade relativa do ar, temperatura e, principalmente, quanto à intensidade luminosa.

Para a realização deste estudo, o material botânico (30 espécimes) em período de senescência foliar foi coletado no município de Santa Cruz das Palmeiras (SP). Também foram utilizados os Catasetum fimbriatum encontrados em ambiente natural no "Campus" da Escola Superior de Agricultura "Luiz de Queiróz" ESALQ-USP, totalizando, assim, 45 espécimes.

Durante a instalação do experimento, tomou-se o cuidado de se padronizar os indivíduos utilizando somente plantas adultas (possuidoras de 5 pseudobulbos), como recomendado por Endsfeldz (1999).
As plantas foram plantadas e submetidas à adubação com NPK, fórmula 20-20-20, a cada 15 dias no verão e a cada 30 dias no inverno (com exceção das plantas em ambiente natural), de acordo com a recomendação para indivíduos maduros e estabelecidos (ENDSFELDZ, 1999).

As plantas nos três tratamentos foram irrigadas a cada dois dias no verão e primavera, e esse procedimento deu-se ao entardecer, e a cada três dias no outono e inverno; nesse período, sempre eram irrigadas pela manhã, como aconselhado por Machado (1998) para a cultura do gênero Catasetum.

As orquídeas foram dispostas de maneira que as extremidades de seus rizomas ficassem encostados nas bordas dos vasos, levando, assim, as extremidades-guias a ocuparem o centro. Não obstante, tal estrutura também foi parcialmente recoberta, como indicado pela literatura orquidófila (ENDSFELDZ, 1999).

Os 45 espécimes de Catasetum fimbriatum foram distribuídos em 3 tratamentos contendo 15 plantas cada um. O primeiro tratamento foi intitulado de "Alta Intensidade Luminosa" (Tratamento 1), pois esses estiveram expostos à intensa luminosidade na casa-de-vegetação, compreendida entre 1300 a $1900 \mu \mathrm{mol} / \mathrm{m}^{2}$ s. O segundo foi denominado de "Baixa Intensidade Luminosa" (Tratamento 2), em razão de esses indivíduos estarem expostos a baixas intensidades luminosas (entre 400 a $650 \mu \mathrm{mol} / \mathrm{m}^{2} \mathrm{~s}$ ), por encontrarem-se em ripado, possuidor de espaçamentos de $3 \mathrm{~cm}$ de largura entre as ripas; e o último de "Intensidade Luminosa Natural" (Tratamento 3), entre 500 a 800 $\mu \mathrm{mol} / \mathrm{m}^{2} \mathrm{~s}$, uma vez que esses estavam situados no estrato dossel das árvores. Portanto, apenas os 30 espécimes coletados no município de Santa Cruz das Palmeiras foram divididos nos dois primeiros tratamentos supracitados.

Em todos os ambientes, os indivíduos dos três tratamentos estiveram expostos a diferentes intensidades luminosas, mensuradas uma vez por semana com um radiômetro (quantômetro) associado a um data-log (marca LiCor, modelo Li -1400) e denominados de acordo com o ambiente lumínico. Também efetuou-se o monitoramento dos valores médios de intensidade luminosa, das taxas de temperatura e umidade relativa do ar nos tratamentos.

Avaliaram-se ainda a quantidade de hastes florais originadas pelas plantas, a quantidade de flores por haste e o tipo de flor obtida, isto é, se foram diclinas masculinas, diclinas femininas ou monoclinas.

Pelos resultados das figuras de dados climáticos (Figuras 1, 2 e 3), evidencia-se a alta capacidade de Catasetum fimbriatum Lindley de sobreviver em ambientes com condições climáticas distintas. 
Intensidade Luminosa $\left(\mu \mathrm{mol} / \mathrm{m}^{2} \mathrm{~s}\right) \times 10$

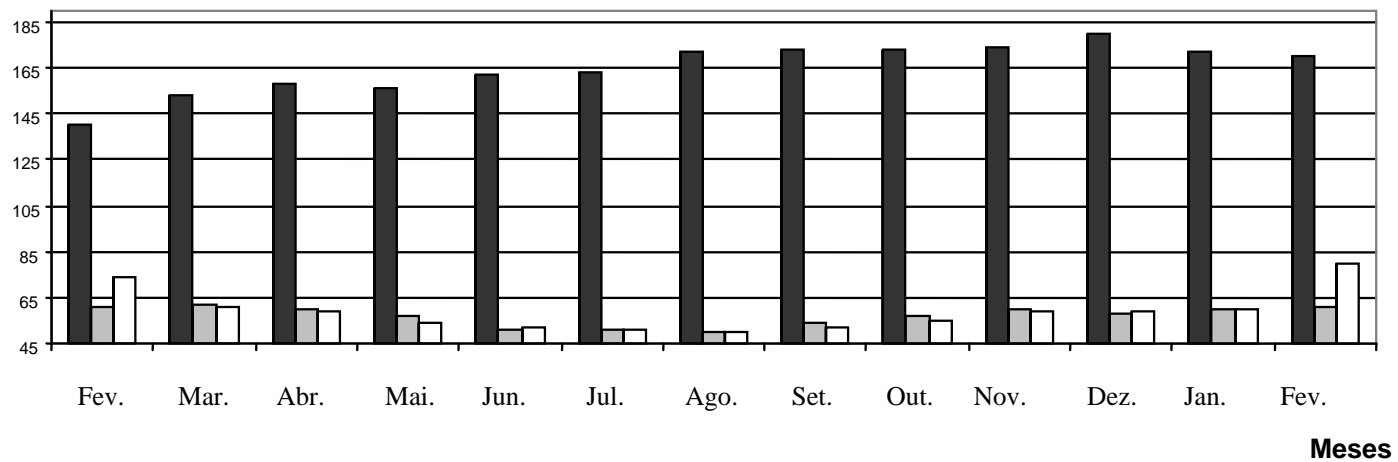

Tratamento $1 \square$ Tratamento $2 \square$ Tratamento 3

FIGURA 1 - Gráfico indicativo dos valores médios de intensidade luminosa dos três tratamentos instalados (tratamento 1 - alta intensidade luminosa, tratamento 2 - baixa intensidade luminosa, tratamento 3 - intensidade luminosa natural).

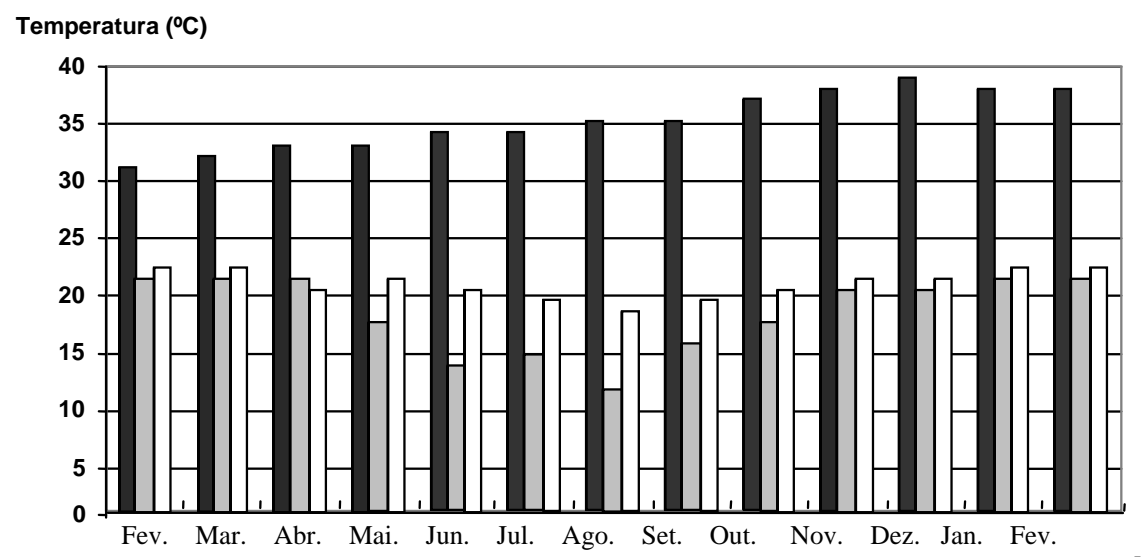

Meses

$\square$ Tratamento $1 \quad \square$ Tratamento $2 \quad \square$ Tratamento 3

FIGURA 2 - Gráfico indicativo dos valores médios de temperatura dos três tratamentos instalados (tratamento 1 - alta intensidade luminosa, tratamento 2 - baixa intensidade luminosa, tratamento 3 - intensidade luminosa natural). 


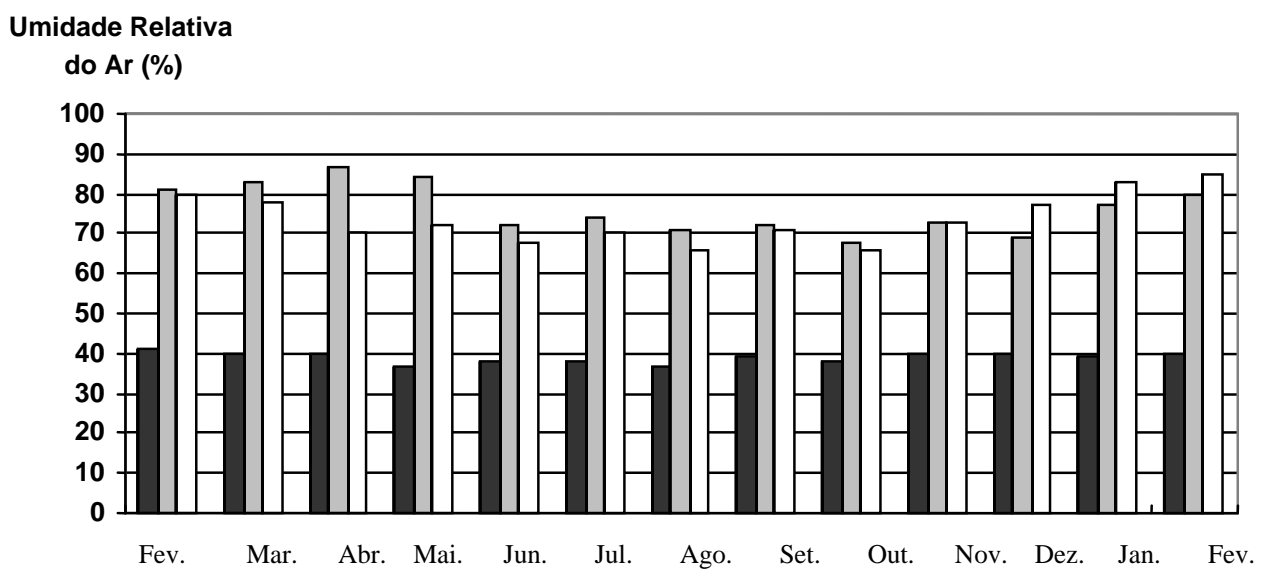

$\square$ Tratamento $1 \quad \square$ Tratamento $1 \quad \square$ Tratamento 1

IMeses

FIGURA 3 - Gráfico indicativo dos valores médios de umidade dos três tratamentos instalados (Tratamento 1 - Alta Intensidade Luminosa, Tratamento 2 - Baixa Intensidade Luminosa, Tratamento 3 - Intensidade Luminosa Natural).

A observação mais importante notada nessas figuras reside no fato de que o tratamento 2 (baixa intensidade luminosa) geralmente apresentou valores inferiores, mas sempre muito próximos em relação à intensidade luminosa e temperatura; porém, suplantou praticamente em todos os momentos em relação à umidade relativa do ar à média observada para o tratamento 3 (figura 3), ocorrendo apenas exceção do mês de novembro de 2000, em que os índices verificados foram iguais, e inferiores em dezembro de 2000, janeiro e fevereiro de 2001. Tal fato mostra-se relevante, pois segundo Zimermam (1991), o detrimento da umidade relativa do ar em relação à intensidade luminosa pode vir acentuar um estresse hídrico, o qual possivelmente aumenta as chances da expressão de flores diclinas femininas, devido ao aumento dos níveis endógenos de etileno.

O tratamento 1 , ao contrário dos outros dois tratamentos, apresentou resultados de intensidade luminosa extremamente elevados (Figura 1), isso provavelmente pelo fato de encontrarem-se dentro de casa-devegetação, onde comumente ocorre o fenômeno de reflexão da luz solar, fenômeno esse capaz de aumentar a intensidade luminosa incidente sobre os indivíduos em estudo. Ainda as médias de temperatura desse ambiente consequientemente prevaleceram como as mais elevadas em relação às medidas dos demais tratamentos, em virtude principalmente da alta exposição solar. A umidade relativa do ar, por sua vez, apresentou-se sempre como a mais baixa entre os três ambientes estudados, em conseqüência de as características ambientais nas condições de estufa exibirem uma alta temperatura, a qual afeta diretamente essa variável, tornando, assim, o local em questão mais seco, sem que haja necessariamente transpiração por parte das plantas.

Pelos resultados referentes à quantidade de hastes florais e flores (Tabelas 1 e 2) verifica-se que os indivíduos submetidos a uma intensidade próxima aos padrões normais ambientais da espécie (tratamento 3) obtiveram um êxito muito maior do que os indivíduos dos demais tratamentos. Possivelmente, isso se deveu ao fato de que alguns indivíduos possuíam maior número de órgãos em conseqüência do maior brotamento ocorrido durante o tratamento em relação aos demais e já se encontravam aclimatados às condições ambientais da área. Sendo assim, em um melhor nível de comparação, deve-se utilizar como base os indivíduos do tratamento 3 , pelo fato de esses terem se desenvolvido em ambiente natural, permitindo, dessa forma, a ampla discussão sobre os indivíduos submetidos a tratamentos sob condições artificiais (tratamentos 1 e 2). 
TABELA 1 - Quantidade de hastes florais e flores formadas em função dos tratamentos. Tratamento 1 (alta intensidade luminosa, entre 1300 a $1900 \mu \mathrm{mol} / \mathrm{m}^{2} \mathrm{~s}$ ), tratamento 2 (baixa intensidade luminosa, entre 400 a $650 \mu \mathrm{mol} / \mathrm{m}^{2} \mathrm{~s}$ ) e tratamento 3 (intensidade luminosa natural, entre 500 a $800 \mu \mathrm{mol} / \mathrm{m}^{2} \mathrm{~s}$ ) (dados simples sem base estatística).

\begin{tabular}{lccc}
\hline & Tratamento 1 & Tratamento 2 & Tratamento 3 \\
\hline Número de hastes florais & 01 & 02 & 19 \\
Número de flores & 14 & 16 & 111 \\
\hline
\end{tabular}

TABELA 2 - Correlação entre o número de hastes florais e flores formadas por indivíduo nos três tratamentos. Tratamento 1 (alta intensidade luminosa, entre 1300 a $1900 \mu \mathrm{mol} / \mathrm{m}^{2} \mathrm{~s}$ ), tratamento 2 (baixa intensidade luminosa, entre 400 a $650 \mu \mathrm{mol} / \mathrm{m}^{2} \mathrm{~s}$ ) e tratamento 3 (intensidade luminosa natural, entre 500 a $800 \mu \mathrm{mol} / \mathrm{m}^{2} \mathrm{~s}$ ). (dados simples sem base estatística).

\begin{tabular}{|c|c|c|c|}
\hline Tratamentos & Indivíduo & Número de hastes florais por indivíduo & Número de flores por haste \\
\hline 1 & $1^{\mathrm{o}}$ & 1 & 14 \\
\hline 1 & $2^{\mathrm{o}} .-15^{\mathrm{o}}$ & 0 & 0 \\
\hline 2 & $1^{\mathrm{o}}$ & 1 & 14 \\
\hline 2 & $2^{\circ}$ & 1 & 2 \\
\hline 2 & $3^{\mathrm{o}} .-15^{\mathrm{o}}$ & 0 & 0 \\
\hline 3 & $1^{\mathrm{o}}$ & 4 & 32 \\
\hline 3 & $2^{\circ}$ & 4 & 30 \\
\hline 3 & $3^{\circ}$. & 4 & 27 \\
\hline 3 & $4^{\mathrm{o}}$ & 3 & 10 \\
\hline 3 & $5^{\mathrm{o}}$ & 1 & 4 \\
\hline 3 & $6^{\circ}$ & 2 & 6 \\
\hline 3 & $7^{\mathrm{o}}$ & 1 & 2 \\
\hline 3 & $8^{\mathrm{o}} .-15^{\mathrm{o}}$ & 0 & 0 \\
\hline
\end{tabular}

Referindo-se aos tratamentos 1 e 2 , comparativamente com o tratamento 3 , pode-se verificar que apenas um dos dois indivíduos alcançaram o florescimento. Esse fato possivelmente pode ser devido às plantas terem sido envasadas e submetidas ao experimento em um curto prazo de tempo, o que segundo Endsfeldz (1998) pode acarretar em um atraso de pelo menos dois anos no florescimento. Deve-se salientar que mesmo o indivíduo do tratamento 1 gerando apenas uma haste floral e o indivíduo do tratamento 2 gerando duas, a quantidade de flores do segundo indivíduo ultrapassou à do primeiro em apenas duas unidades. Esse fato permite inferir que o florescimento em Catasetum fimbriatum Lindley é positivamente influenciado por intensa luminosidade, talvez pela associação dos mecanismos genéticos e fisiológicos envolvidos com a adaptação da espécie a locais fisicamente estressados. Pode-se observar também que o comprimento da haste floral do indivíduo submetido ao tratamento 1 foi maior em $4,2 \mathrm{~cm}$, do que o comprimen- 
to médio das hastes florais geradas pelo indivíduo submetido ao tratamento 2.

Em Catasetum fimbriatum Lindley, a ocorrência de flores diclinas femininas se dá, possivelmente, quando o nível endógeno de etileno presente eleva-se em virtude das injúrias e do estresse causado nos tecidos vegetais pelo aumento da intensidade luminosa. Sendo assim, o fator preponderante para tal plasticidade é a intensidade luminosa, seguida pelos demais fatores ambientais já mencionados.

Nos experimentos instalados, provavelmente a não-ocorrência desses tipos de flores deve principalmente estar relacionada com as constantes variações climáticas ocorrentes em todos os ambientes do globo terrestre (MULKEY et al., 1996). Esse fenômeno também foi observado no período de estudo, durante o qual a sazonalidade não apresentou o mesmo padrão do ano anterior. Isso pode ser estabelecido pelo fato de que mesmo no tratamento 1 (Figura 1), plantas que supostamente deveriam gerar flores diclinas femininas não o fizeram, pois a intensidade luminosa necessária para a ocorrência de tal tipo de flor não se perpetuou pelo tempo mínimo necessário para sua indução. Tal plasticidade fenotípica ocorre muito provavelmente em virtude da ação do etileno, sintetizado pelas respostas transmitidas principalmente pelas fotoconversões do fitocromo ao interagirem com variados estímulos ambientais como disponibilidade hídrica, umidade relativa do ar, nutrição e temperatura (TAIZ e ZEIGER, 1998).

A não-perpetuação da intensidade luminosa necessária para a ocorrência das flores diclinas femi- ninas pode ser explicada pela comparação dos dados climáticos dos anos de 1999 e 2000 (Tabela 3), justamente na época em que ocorre a floração dos indivíduos submetidos à intensa luminosidade, caracterizada do final do mês de outubro ao início do mês de janeiro. Esse evento alcança maior expressão e maior número de indivíduos que florescem nos meses de novembro e dezembro, seja em ambiente natural ou no tratamento instalado.

Fatores como radiação total global, insolação e temperatura, os quais são capazes de propiciar um aumento na síntese de etileno (Tabela 3 ) devido ao estresse que geram, evidenciam pela comparação das médias maior valor numérico no ano de 1999, em que se verificou o aparecimento de flores diclinas femininas. No ano de 2000, fatores como precipitação e umidade relativa do ar apresentaram um valor numérico médio mais elevado que em relação ao ano de 1999, fato esse, possivelmente responsável pelo surgimento exclusivo de flores diclinas masculinas, uma vez que não houve condições estressantes e, portanto, provavelmente os níveis de etileno endógeno permaneceram inalterados, isto é, sem qualquer acréscimo, o que corrobora as observações de Taiz e Zeiger (1998).

Também o regime hídrico em 1999 foi menor que o verificado em relação a 2000, durante o qual ocorreram apenas 13 e 14 dias de chuva, respectivamente, nos meses de novembro e dezembro, ao passo que no mesmo período de 2000, verificaram-se 16 e 19 dias de chuva, respectivamente, o que acarreta uma menor quantidade de radiação solar diária, além de

TABELA 3 - Variáveis climáticas dos meses de novembro e dezembro dos anos de 1999 e 2000, dadas em valor médio.

\begin{tabular}{ccccccc}
\hline Mês/Ano & $\begin{array}{c}\text { Radiação total } \\
\text { Global } \\
\mathbf{c a l} / \mathbf{c m})\end{array}$ & $\begin{array}{c}(\mathbf{2} \\
\text { Insolação } \\
\mathbf{( h / d )}\end{array}$ & $\begin{array}{c}\text { Precipitação } \\
(\mathbf{m m})\end{array}$ & $\begin{array}{c}\text { Umidade } \\
\text { Relativa Ar } \\
(\mathbf{\%})\end{array}$ & $\begin{array}{c}\text { Temperatura } \\
\text { Máxima } \\
\left({ }^{\mathbf{0}} \mathbf{C}\right)\end{array}$ & $\begin{array}{c}\text { Dias de } \\
\text { chuva }\end{array}$ \\
$\begin{array}{c}\text { Novembro de } \\
1999\end{array}$ & 480 & 7,0 & 1,7 & 72 & 29,5 & 13 \\
$\begin{array}{c}\text { Dezembro de } \\
1999\end{array}$ & 508 & 7,2 & 8,7 & 78 & 30,6 & 14 \\
$\begin{array}{c}\text { Novembro de } \\
2000\end{array}$ & 465 & 6,8 & 8,0 & 77 & 29 & 16 \\
$\begin{array}{c}\text { Dezembro de } \\
2000\end{array}$ & 448 & 5,6 & 6,3 & 82 & 29 & \\
\hline
\end{tabular}


uma maior disponibilidade hídrica. Em suma, mesmo que a intensidade luminosa tenha atingido valores próximos de $1900 \mu \mathrm{mol} / \mathrm{m}^{2} \mathrm{~s}$ no tratamento 1 (Figura 1), esses valores não foram alcançados diariamente, não sendo suficiente, portanto, para gerar o estímulo responsável e fundamental para a formação de flores diclinas femininas de Catasetum fimbriatum Lindley. Convém salientar que pelo fato de existirem orquídeas vivendo em ambiente natural no "Campus"da Escola Superior de Agricultura "Luiz de Queiróz", ESALQ-USP, foi possível um estudo com características ecológicas distintas, sendo esse, portanto, o motivo de apenas medir-se a intensidade luminosa, e não controlá-la artificialmente, buscando, assim, a compreensão dos fatores que controlam a plasticidade das flores de Catasetum fimbriatum na natureza.

Com base nos resultados obtidos, é possível concluir que os ciclos vitais ocorridos nas plantas de $\mathrm{Ca}$ tasetum fimbriatum Lindley submetidas a diferentes condições climáticas iniciaram-se em épocas distintas do ano, resultando em desuniformidade entre os indivíduos em relação a esses fenômenos, e indicando a alta capacidade dessa espécie na formação de ecótipos.

\section{REFERÊNCIAS BIBLIOGRÁFICAS}

COSGROVE, D. Biophysical control of plant cell growth. Annual Review of Plant Physiology, Palo Alto, v. 37, p. 377-405, 1987.

ENDSFELDZ, W. F. Galeria de espécies. O Mundo das Orquídeas, [S.1.], v. 2, p. 22-27, 1998.
ENDSFELDZ, W. F. Características muito peculiares. Natureza, Porto Alegre, p. 26-36, 1999. Edição especial.

GATES, D. M. Biophysical ecology. New York: Springer-Verlag, 1981. $432 \mathrm{p}$.

HOEHNE, F. C. As plantas ornamentais da flora brasílica. Boletim de Agricultura, São Paulo, v. 1, p. $247-$ 273, 1938.

MACHADO, E. F. Catasetum, uma orquídea diferente. O Mundo das Orquídeas, [S.1.], v. 4, p. 5-6, 1998.

MULKEY, S. S.; CHAZDON, R. L.; SMITH, A. P. Tropical forest plant ecophysiology. New York: Chapman \& Hall, 1996. 625 p.

NOBEL, P. S. Physicochermical and environmental plant physiology. New York: Academic, 1991. 452 p.

RAVEN, P. H.; EVERT, R. E.; EICHHORN, S. E. Biologia vegetal. 5. ed. Rio de Janeiro: Guanabara Koogan, 1996. 728 p.

TAIZ, L.; ZEIGER, E. Plant physiology. 2. ed. Sunderlands: Sinauer, 1998. 792 p.

ZIMERMAM, G. K. Ecological correlates of labile espression in the orchid Catasetum viridiflavum. Ecology, Durham, v. 72, n. 2, p. 597-608, 1991. 